\title{
Preparation of a Textile-Based Dye-Sensitized Solar Cell
}

\author{
Klaus Opwis, ${ }^{1}$ Jochen Stefan Gutmann, ${ }^{1}$ Ana Rosa Lagunas Alonso, \\ Maria Jesus Rodriguez Henche, ${ }^{2}$ Mikel Ezquer Mayo, ${ }^{2}$ Fanny Breuil, ${ }^{3}$ \\ Enrico Leonardi, ${ }^{4}$ and Luca Sorbello ${ }^{4}$ \\ ${ }^{1}$ Deutsches Textilforschungszentrum Nord-West gGmbH, 47798 Krefeld, Germany \\ ${ }^{2}$ Centro Nacional de Energías Renovables, 31621 Sarriguren, Spain \\ ${ }^{3}$ Eurecat Centro Tecnologico de Cataluña, 08301 Mataró, Spain \\ ${ }^{4}$ Dyesol Italia, 00187 Rome, Italy \\ Correspondence should be addressed to Klaus Opwis; opwis@dtnw.de
}

Received 29 March 2016; Revised 8 July 2016; Accepted 12 July 2016

Academic Editor: Vishal Mehta

Copyright (C) 2016 Klaus Opwis et al. This is an open access article distributed under the Creative Commons Attribution License, which permits unrestricted use, distribution, and reproduction in any medium, provided the original work is properly cited.

\begin{abstract}
Solar energy conversion is an object of continuous research, focusing on improving the energy efficiency as well as the structure of photovoltaic cells. With efficiencies continuously increasing, state-of-the-art PV cells offer a good solution to harvest solar energy. However, they are still lacking the flexibility and conformability to be integrated into common objects or clothing. Moreover, many sun-exposed surface areas are textile-based such as garments, tents, truck coverings, boat sails, and home or outdoor textiles. Here, we present a new textile-based dye-sensitized solar cell (DSC) which takes advantage from the properties inherent to fabrics: flexibility, low weight, and mechanical robustness. Due to the necessary thermostability during manufacturing, our DSC design is based on heat-resistant glass-fiber fabrics. After applying all needed layers, the overall structure was covered by a transparent and simultaneously conductive protective film. The light and still flexible large-area devices (up to $6 \mathrm{~cm}^{2}$ per individual unit) are working with efficiencies up to $1.8 \%$ at $1 / 5$ of the sun. Stability tests assure no loss of photovoltaic activity over a period of at least seven weeks. Therefore, our technology has paved the way for a new generation of flexible photovoltaic devices, which can be used for the generation of power in the mentioned applications as well as in modern textile architecture.
\end{abstract}

\section{Introduction}

The conversion of sunlight into electric energy is the most environmentally friendly and nonhazardous alternative to fossil and fissionable resources. Along with the aim to increase the efficiency, former and present R\&D focuses on the optimization of photovoltaic (PV) structures and the development of new photoactive materials.

Currently, most photovoltaic devices are still fabricated for large-scale electric power generation either in centralized solar parks or as building integrated photovoltaics (BIPV). For these applications, rigid, weather-proof, and long-term stable devices are desired. The common material of choice is monocrystalline or multicrystalline silicon, which have high average energy-conversion efficiencies in the range of 18 to 26 percent. Besides silicon, other semiconducting alternative materials have been developed and tested within the previous decades, which differ strongly in terms of production costs on the one hand and the efficiency on the other hand. Well-described types are III-V (GaAs, InP, and GaInP), chalcogenide (CIGS, CdTe, and CZTS), and multijunction cells with up to five different p-n-junctions. Furthermore, in recent years organic, dye-sensitized, and perovskite solar cells have proven their large potential within the present and future photovoltaic market [1-3]. In particular, the dyesensitized solar cell (DSC), which was introduced by O'Regan and Grätzel in the early 1990s, seems to be the most promising candidate for an enduring launch into several commercial products. Compared to other types of solar cells, DSC are much less sensitive to the angle of incidence of radiation, shadowing, and ambient temperature changes. They perform over the most extensive range of light conditions enabling the energy production even in the early morning, in the late 
afternoon, or on cloudy days. They combine high energyconversion efficiencies and sufficient robustness towards environmental impact and, therefore, sufficient life-time. The base materials are comparatively inexpensive. In addition, the layer thickness of the used direct semiconductors can be reduced on micron or even nanoscale. This allows the use of cost-effective thin-layer and/or printing technologies and the integration of lightweight and flexible DSC structures into countless commercial products of our day-to-day life [3-8].

Besides plastics and film applications [3, 9-11], which have already arrived to a commercial level, photovoltaic textiles have attracted increasing attention in recent years since they are often exposed directly to sunlight and represent ideal substrates for the conversion of solar energy into electricity. We refer to outdoor textiles such as blinds, tents, tarpaulins, sails, and last but not least the important increasing market of textile architecture, which has an outstanding potential to form the basis for flexible, lightweight, and robust PV structures.

As a result, a large effort has been put into research activities focusing on innovative concepts for textile-based DSC. The major challenge is to combine properties and demands of the photovoltaic concept (and processing) with inherent properties of fibrous substrates (and typical textile processing).

In literature, several successful DSC designs on fibrous materials such as paper, wires, fibers, strings, or textiles are listed [12-23]. However, in most cases these approaches are aimed at the production of single fibers or wires with photovoltaic activity, concealing the need of additional sensitive processing steps afterwards, for example, weaving, which could impair the cell performance dramatically. Furthermore, the length of those one-dimensional cells is limited to a certain extent. This impedes the (textile) processing additionally. On contrary to the most common single-fiber approaches, our investigations are focused on already woven textile structures taking advantage from the properties inherent to fabrics: flexibility, low weight, and mechanical robustness. We report on the preparation of a two-dimensional textile-based dye-sensitized solar cell and the used deposition techniques of all further needed conductive, photoactive, and protective layers to achieve flexible, light, mechanically strong, and comparatively large-area devices.

\section{Experimental}

2.1. Production of Textile-Based DSC. A commercial high flexible glass-fiber fabric (Interglas, Germany) with the following characteristics was used as basic substrate for the deposition of the DSC structure: mass per unit area $107 \mathrm{~g} / \mathrm{m}^{2}$, thickness $0.09 \mathrm{~mm}$, tensile strength (warp) $250 \mathrm{~N} / \mathrm{cm}$, tensile strength (weft) $235 \mathrm{~N} / \mathrm{cm}$, thermostability (short-time) $600^{\circ} \mathrm{C}$, and thermostability (permanent) $500^{\circ} \mathrm{C}$. Afterwards the glass-fiber fabric was covered with a thin polyamide film by roll-to-roll procedure followed by electron beam deposition or sputtering of a titanium layer. Titanium dioxide DSL18NR-AO (Dyesol) was deposited by screen-printing. The cured material $\left(500^{\circ} \mathrm{C}\right.$ for $5 \mathrm{~min}$ ) was sensitized by various ruthenium-based dyestuffs. As a transparent counter electrode, a commercial PEN + ITO film was selected (CPFilms). The film has a thickness of $125 \mu \mathrm{m}$ with a transparency of $75 \%$ at $550 \mathrm{~nm}$. The sheet resistance amounts to $15 \Omega / \mathrm{sq}$. On the ITO side of the film, the catalyst layer was deposited by the chemical reduction of $\mathrm{H}_{2} \mathrm{PtCl}_{6}$ at room temperature resulting in homogeneous Pt clusters on the substrate surface. After the adding of the electrolyte (EL-HSE, Dyesol), the textile part (glass-fiber fabric $+\mathrm{PA}$ layer $+\mathrm{Ti}+$ dye-sensitized $\mathrm{TiO}_{2}$ ) was covered with the counter electrode part $(\mathrm{PEN}+\mathrm{ITO}+\mathrm{Pt})$ yielding the flexible textile-based DSC. The overall structure was sealed by the use of special epoxy and thermoplastic foils (DuPont, Dyesol) to achieve the final textile-based DSC.

2.2. Analytics/Characterization. After the Ti deposition, the samples were characterized by means of optical microscopy and mechanical profilometry. Surface resistances of the electrodes were measured via 4-point probe.

The electrical characterization of the samples was performed at Standard Test Conditions (STC) in accordance with the standard IEC:60904-1-Ed.2:2006, under irradiation with a steady-state class A solar simulator according to IEC:609049-Ed.2:2007. The $I V$-curves at STC $\left(1000 \mathrm{~W} / \mathrm{m}^{2}, 25^{\circ} \mathrm{C}, \mathrm{AM}\right.$ $1.5 \mathrm{G}$ spectrum) and at various values of irradiance were measured. During the measurement, the samples were kept at a constant temperature using a vacuum chuck.

The spectral mismatch, caused by the deviation of the simulator spectrum from the standard solar spectrum AM1.5G (IEC:60904-3-Ed.2:2008) in combination with the different spectral responses of reference cell and device under test, was calculated according to the standard IEC:60904-7Ed.3:2008 and corrected consequently.

For the spectral mismatch correction, the spectral distribution of the solar simulator was measured with a calibrated spectroradiometer, and the spectral response of the solar cell was measured with a filter monochromator according to IEC:60904-8-Ed.2:1998.

In order to study the influence of the temperature on the electrical behavior of the cells, CENER carried out $I V$ curve measurements at different temperatures, maintaining the irradiance value constant at $830 \mathrm{~W} / \mathrm{m}^{2}$.

Outdoor $I V$-curve measurements were carried out on a sunny day, placing the PV cells on a solar tracker perfectly sun-oriented. The global irradiance was measured using a calibrated pyranometer, and the cell temperature was monitored with a calibrated thermocouple.

The spectral response measurements were performed using a filter monochromator based system according to the procedure established in the IEC:60904-8:2008 standard. The frequency of the chopper was around $4 \mathrm{~Hz}$, and the bias light used was a white light with an intensity value around $100 \mathrm{~W} / \mathrm{m}^{2}$. For complementary information, the measurement of the spectral reflectance of the cells was carried out using a calibrated spectroradiometer and an integrating sphere.

In the first part of the stability study, textile-based DSC were irradiated with a constant intensity of $830 \mathrm{~W} / \mathrm{m}^{2}$, and the temperature of the cell was maintained almost 


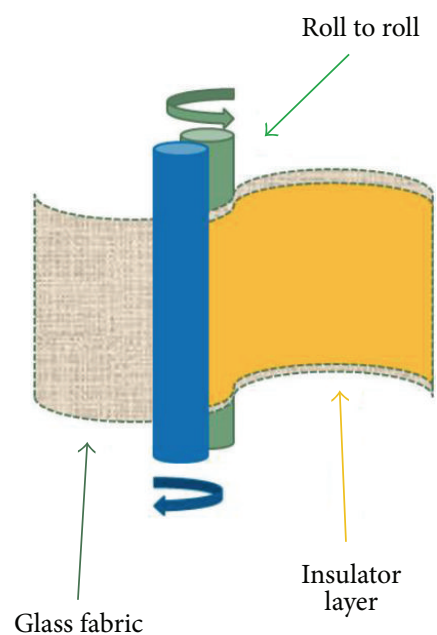

Roll-to-roll technique

(a)

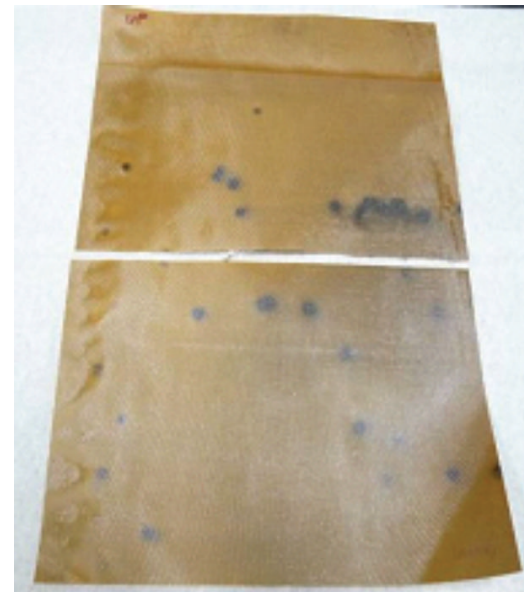

Glass-fiber fabric + polyamide film

(b)

FIGURE 1: Roll-to-roll technique used (a) to cover the glass-fiber fabric with a polyamide film (b).
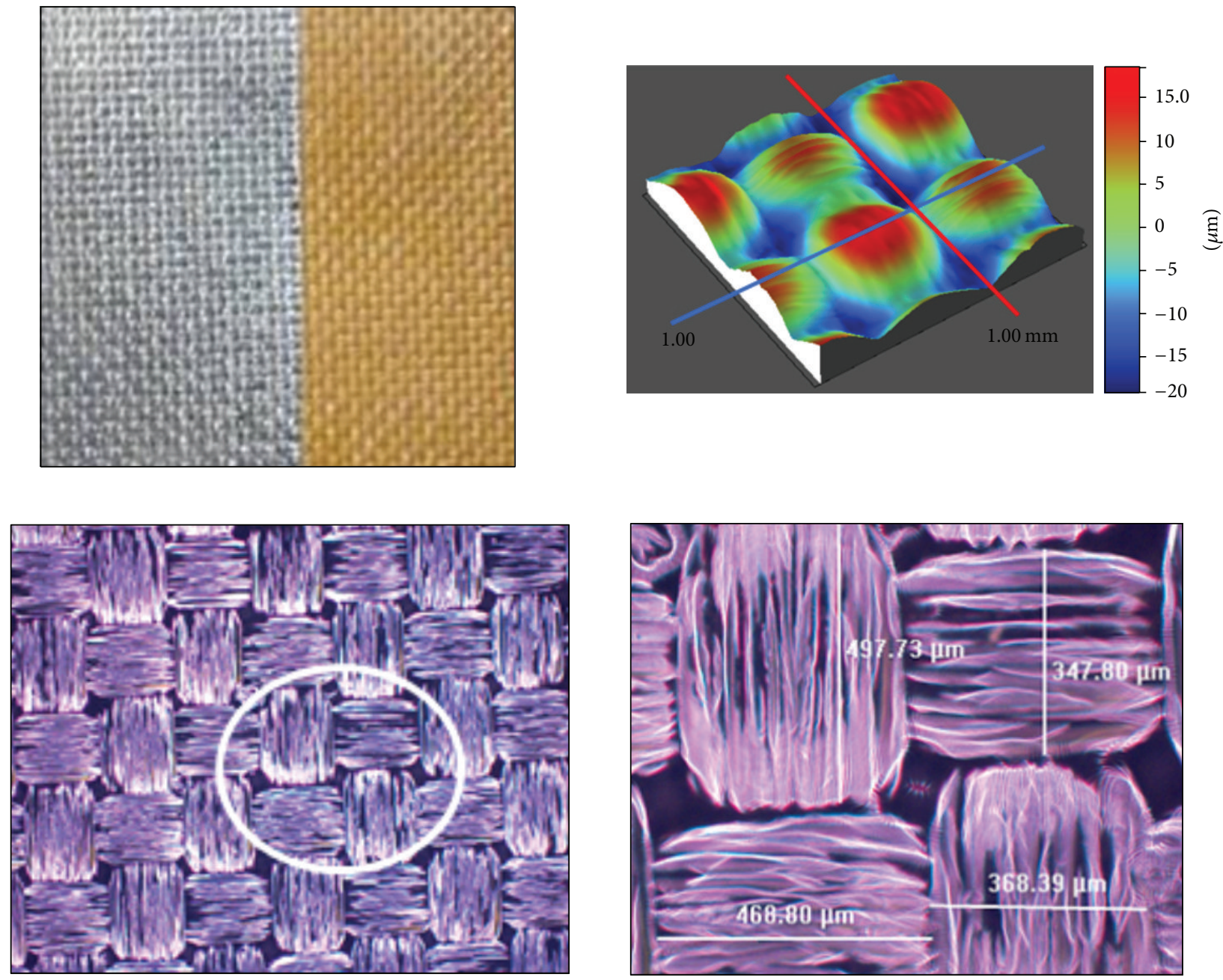

FIGURE 2: Optical characterization of Ti layers deposited on the polyamide covered glass-fiber fabric by eBeam. 


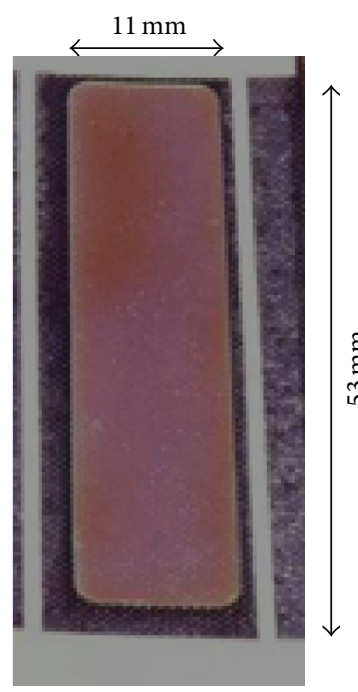

(a)

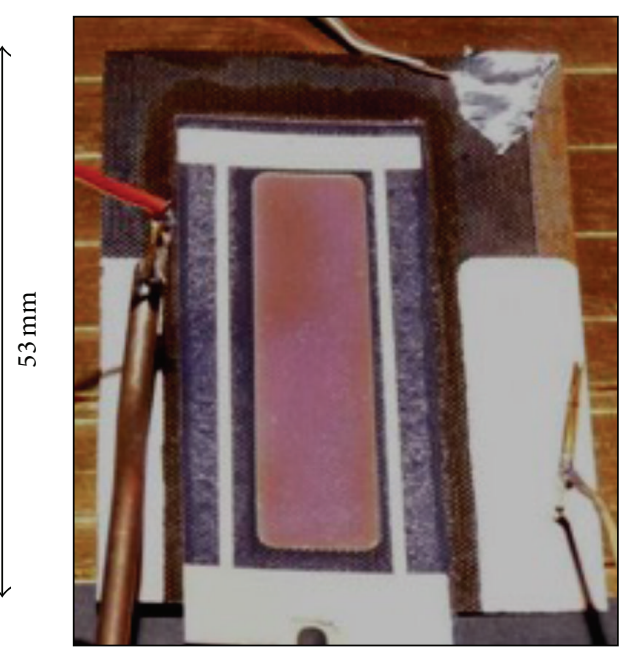

(b)

FIgURE 3: Final textile-based DSC (a) and 4-point configuration used in the $I V$-curve measurement (b).

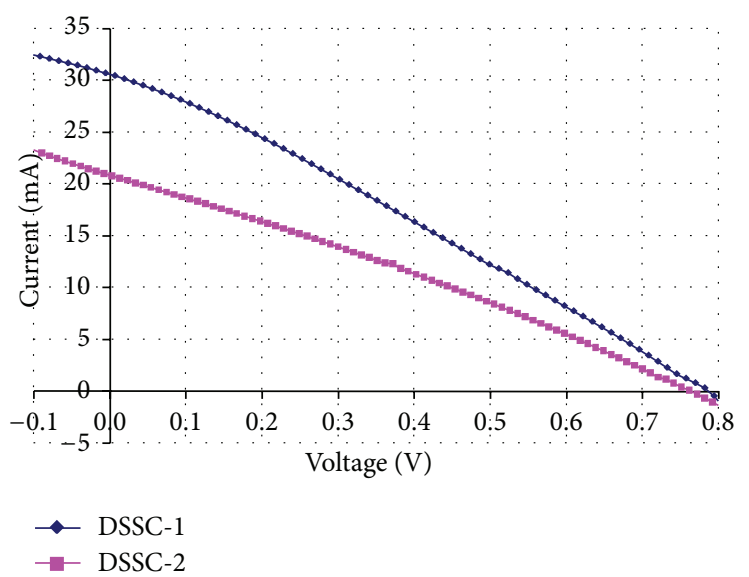

\begin{tabular}{|c|c|c|c|c|c|c|c|c|}
\hline Solar cell & $\begin{array}{c}V_{\mathrm{oc}} \\
(\mathrm{V})\end{array}$ & $\begin{array}{c}I_{\mathrm{sc}} \\
(\mathrm{mA})\end{array}$ & $\begin{array}{c}P_{\max } \\
(\mathrm{mW})\end{array}$ & $\begin{array}{c}V_{\max } \\
(\mathrm{V})\end{array}$ & $\begin{array}{c}I_{\max } \\
(\mathrm{mA})\end{array}$ & $\begin{array}{c}\mathrm{FF} \\
(\%)\end{array}$ & $\begin{array}{c}\text { Area } \\
\left(\mathrm{cm}^{2}\right)\end{array}$ & $\begin{array}{c}\mathrm{Ef} \\
(\%)\end{array}$ \\
\hline DSC-1 & 0.79 & 30.6 & 6.6 & 0.37 & 17.6 & 27.4 & 6.0 & 1.10 \\
\hline DSC-2 & 0.75 & 20.8 & 4.5 & 0.35 & 13.0 & 28.7 & 6.0 & 0.75 \\
\hline
\end{tabular}

FIGURE 4: $I V$-curves of two samples of textile-based DSC under STC.

constantly between $30^{\circ} \mathrm{C}$ and $31^{\circ} \mathrm{C}$. In order to study the stability/durability of the electrical behavior of the cells over time, $I V$-curves (irradiance: $830 \mathrm{~W} / \mathrm{m}^{2}$; temperature: $25^{\circ} \mathrm{C}$ ) of the DSC cells were measured in 3 consecutive days and 45 days after the first measurement. The PV cells were stored in dark conditions between measurements. In addition, the open circuit voltage, the current density, and the fill factor of the DSC samples were measured over a period of 7 weeks.

\section{Results and Discussion}

3.1. Structure of Textile-Based DSC. In accordance to typical DSC, our textile-based DSC structure is a composite of several materials. The layer-by-layer structure (schematically shown in Table 1) consists of the textile substrate (1), which serves as a flexible, lightweight but mechanically strong support for all the following layers. Each layer shows materialspecific characteristics and must fulfill DSC requirements in terms of thermostability, roughness, adhesion, conductivity, photovoltaic activity, transparency, barrier properties, and flexibility. In addition, the overall structure must be liquidproof to avoid leakage of the electrolyte.

To achieve a flat, thermostable, and liquid-proof substrate, the glass-fiber fabric was covered with a thin polyamide film (2) by a simple roll-to-roll procedure (Figure 1).

On this improved material, a titanium layer (3) was deposited to turn the fiber glass into a conductive substrate, which can act as the bottom electrode. The Ti films were 


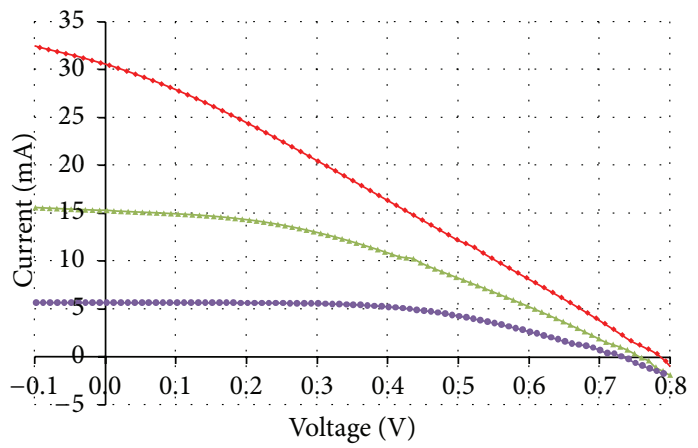

$$
\begin{aligned}
& \rightarrow 1000 \mathrm{~W} / \mathrm{m}^{2} \quad-200 \mathrm{~W} / \mathrm{m}^{2} \\
& \triangle 500 \mathrm{~W} / \mathrm{m}^{2}
\end{aligned}
$$

\begin{tabular}{|c|c|c|c|c|c|c|c|c|}
\hline $\begin{array}{c}\text { Irradiance } \\
\left(\mathrm{W} / \mathrm{m}^{2}\right)\end{array}$ & $\begin{array}{c}V_{\mathrm{oc}} \\
(\mathrm{V})\end{array}$ & $\begin{array}{c}I_{\mathrm{sc}} \\
(\mathrm{mA})\end{array}$ & $\begin{array}{c}P_{\max } \\
(\mathrm{mW})\end{array}$ & $\begin{array}{c}V_{\max } \\
(\mathrm{V})\end{array}$ & $\begin{array}{c}I_{\max } \\
(\mathrm{mA})\end{array}$ & $\begin{array}{c}\mathrm{FF} \\
(\%)\end{array}$ & $\begin{array}{c}\text { Area } \\
\left(\mathrm{cm}^{2}\right)\end{array}$ & $\begin{array}{c}\mathrm{Ef} \\
(\%)\end{array}$ \\
\hline 1000 & 0.79 & 30.6 & 6.6 & 0.37 & 17.6 & 27.4 & 6.0 & 1.10 \\
\hline 500 & 0.75 & 15.3 & 4.5 & 0.42 & 10.7 & 39.3 & 6.0 & 1.51 \\
\hline 200 & 0.71 & 5.7 & 2.2 & 0.46 & 4.8 & 54.1 & 6.0 & 1.83 \\
\hline
\end{tabular}

FIGURE 5: $I V$-curves at 3 different irradiance levels for DSC-1.
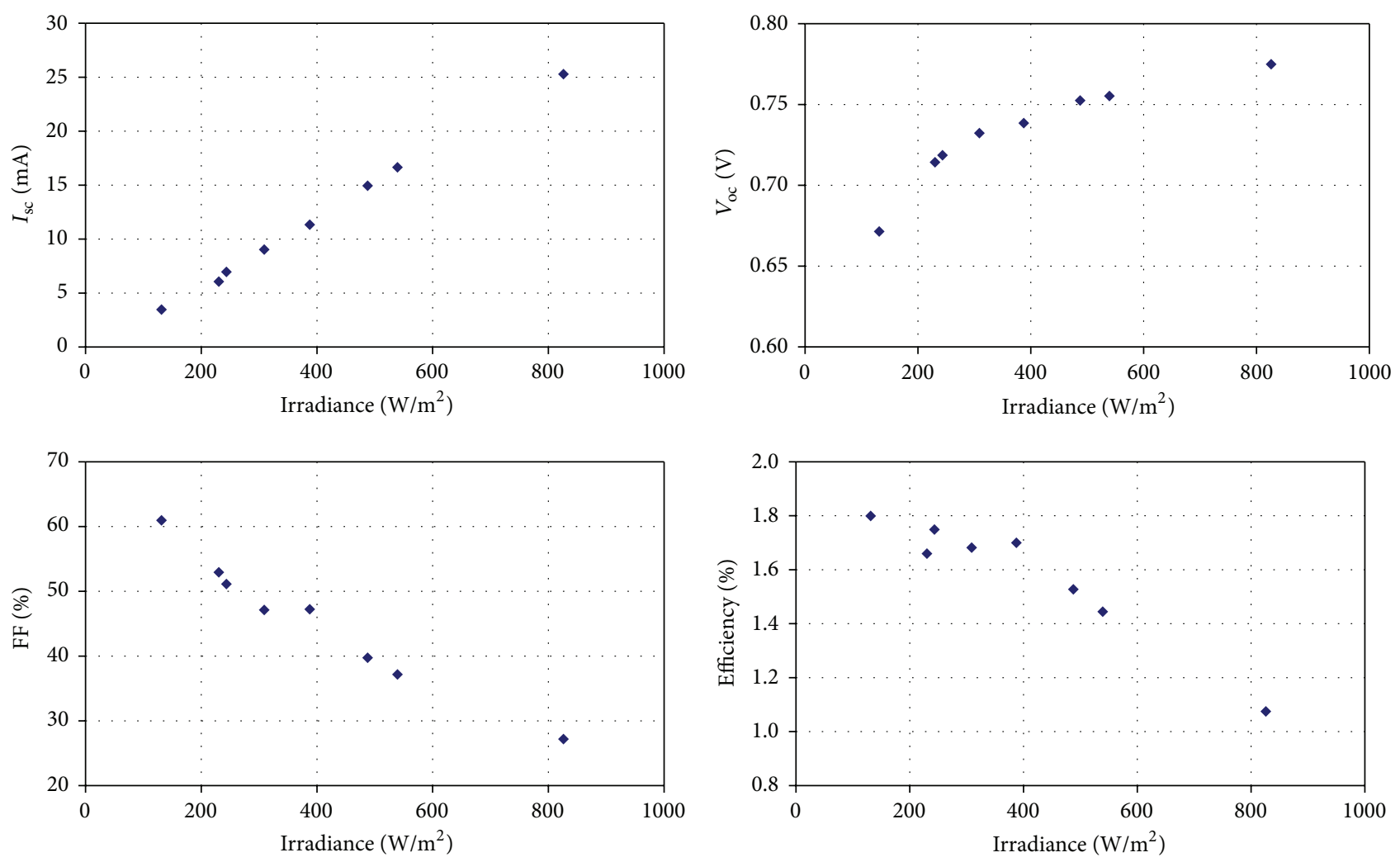

FIGURE 6: Variation of the main electrical parameters of DSC-1 with the irradiance level.

grown by two different deposition techniques: electron beam (eBeam) and sputtering. After the Ti deposition, the samples were characterized by means of optical microscopy and mechanical profilometry. Exemplarily, Figure 2 shows images of the materials after eBeam deposition of Ti. Independently from the $\mathrm{Ti}$ deposition technique used, the sample surfaces maintained the substrate topography. Moreover, both technologies lead to quite homogeneous films with good adherence to the substrate. Surface resistances lower than $3 \Omega /$ sq were found indicating sufficient conductivity. 
TABLE 1: Textile-based DSC device structure and essential requirements of the layers.

\begin{tabular}{|c|c|c|c|}
\hline \multicolumn{4}{|r|}{ Sun light } \\
\hline 8 & Cover & $\begin{array}{l}\text { Special epoxy and } \\
\text { thermoplastic foils }\end{array}$ & Transparency and impermeability towards the electrolyte \\
\hline 7 & Upper electrode & Thin PEN/ITO film & Conductivity and transparency \\
\hline 6 & Catalyst & Pt & \multirow[t]{3}{*}{ Good adhesion } \\
\hline 5 & Electrolyte & $\mathrm{I}^{-} / \mathrm{I}_{3}^{-}$ & \\
\hline 4 & Active layer & $\mathrm{TiO}_{2}$ and dyestuff & \\
\hline 3 & Bottom electrode & $\mathrm{Ti}$ & \multirow{2}{*}{$\begin{array}{c}\text { Conductivity, thermoresistance, high flexibility, and good adhesion } \\
\text { Thermoresistance, impermeability towards the electrolyte, high flexibility, and good } \\
\text { adhesion }\end{array}$} \\
\hline 2 & Smoothing layer & Polyamide coating & \\
\hline 1 & Substrate & Glass-fiber fabric & Thermoresistance, high flexibility, being light, and mechanical strength \\
\hline & Layer & Material used & Properties/requirements \\
\hline
\end{tabular}

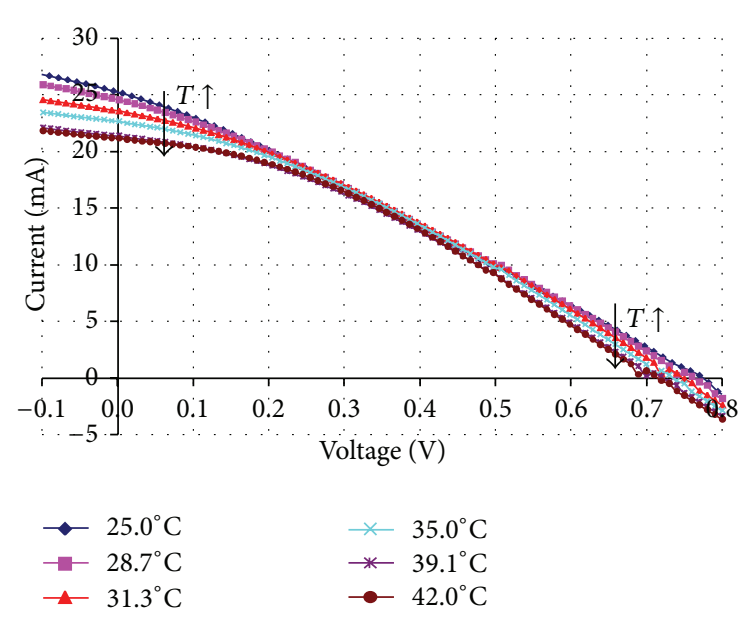

FIGURE 7: DSC-1 IV-curves measured at 6 different temperatures at an irradiance value of $830 \mathrm{~W} / \mathrm{m}^{2}$.

In the following step, titanium dioxide DSL-18NR-AO was deposited by screen-printing and cured for 5 minutes at $500^{\circ} \mathrm{C}$ to achieve a nanoporous structure of the titania, which allows a high uptake of various ruthenium-based dyestuffs. The dye-sensitized titania forms the photoactive layer (4) that absorbs the sun light yielding electric charges. This short-term but high-temperature curing step clarifies the necessity of all previous layers to be thermostable in the range of $500^{\circ} \mathrm{C}$ for a certain time. In the field of conventional textile materials, only glass-fiber fabrics fulfill this essential requirement.

A commercial PEN-ITO film (7) was selected as a transparent counter electrode. The film has a thickness of $125 \mu \mathrm{m}$ with a transparency of $75 \%$ at $550 \mathrm{~nm}$. The sheet resistance of $15 \Omega /$ sq is sufficient.

On the ITO side of the film, the catalyst layer (6) was deposited by the chemical reduction of $\mathrm{H}_{2} \mathrm{PtCl}_{6}$ at room temperature resulting in homogeneous Pt clusters on the substrate surface. After adding the electrolyte (5), the textile part (glass-fiber fabric $+\mathrm{PA}$ layer $+\mathrm{Ti}+$ dye-sensitized $\mathrm{TiO}_{2}$ ) was covered with the counter electrode part $(\mathrm{PEN}+\mathrm{ITO}+\mathrm{Pt})$ yielding the flexible textile-based DSC. The overall structure was sealed by a special epoxy and thermoplastic foils (8) to protect the structure from environmental conditions. Our textile-based DSC device with the size of nearly $6 \mathrm{~cm}^{2}$ is shown in Figure 3(a).

\subsection{Photovoltaic Performance of Textile-Based DSC}

3.2.1. IV-Curve Measurement under Standard and Nonstandard Test Conditions. In order to characterize the textilebased DSC electrically in terms of its photovoltaic performance, we started with $I V$-curve measurement under Standard Test Conditions (STC) using the configuration shown in Figure 3(b) providing the results summarized in Figure 4. The DSC devices show a significant photovoltaic activity with an average efficiency of nearly $1.0 \%$.

Solar cells normally present a different electrical behavior depending on the irradiance level, and the photovoltaic efficiency of the cells can change significantly depending on the irradiance value. As a consequence of this and in addition to the STC measurements, we measured the $I V$-curve of the DSC-1 cell at different irradiance values, maintaining the AM1.5G spectrum and the $25^{\circ} \mathrm{C}$ temperature. As an example, in Figure 5, the $I V$-curves obtained for 3 representative levels of irradiance $\left(1000 \mathrm{~W} / \mathrm{m}^{2}, 500 \mathrm{~W} / \mathrm{m}^{2}\right.$, and $\left.200 \mathrm{~W} / \mathrm{m}^{2}\right)$ are shown to have joined to the electrical parameters extracted from them. The represented $I V$-curves were obtained by applying the correction value due to the spectral mismatch factor.

As can be seen in Figure 5, the electrical behavior of the cell presents a clear dependency with the irradiance level. The efficiency of the cell improves significantly when the irradiance decreases, mainly due to the significant increase of the Fill Factor (FF) at low irradiance levels.

Figure 6 shows the variation of the main electrical parameters $\left(V_{\mathrm{oc}}, I_{\mathrm{sc}}, \mathrm{FF}\right.$, and efficiency) as a function of the irradiance level. All the represented values are extracted from the $I V$-curves measured at different irradiances, taking into account the spectral mismatch factor.

The value of the $I_{\mathrm{sc}}$ increases linearly with the irradiance level. This fact is completely reasonable because, normally, the $I_{\mathrm{sc}}$ value is directly proportional to the irradiance value. In addition, $V_{o c}$ increases with the irradiance level due to the increasing electron injection into titania at higher illumination, which pushes the Fermi level up. 

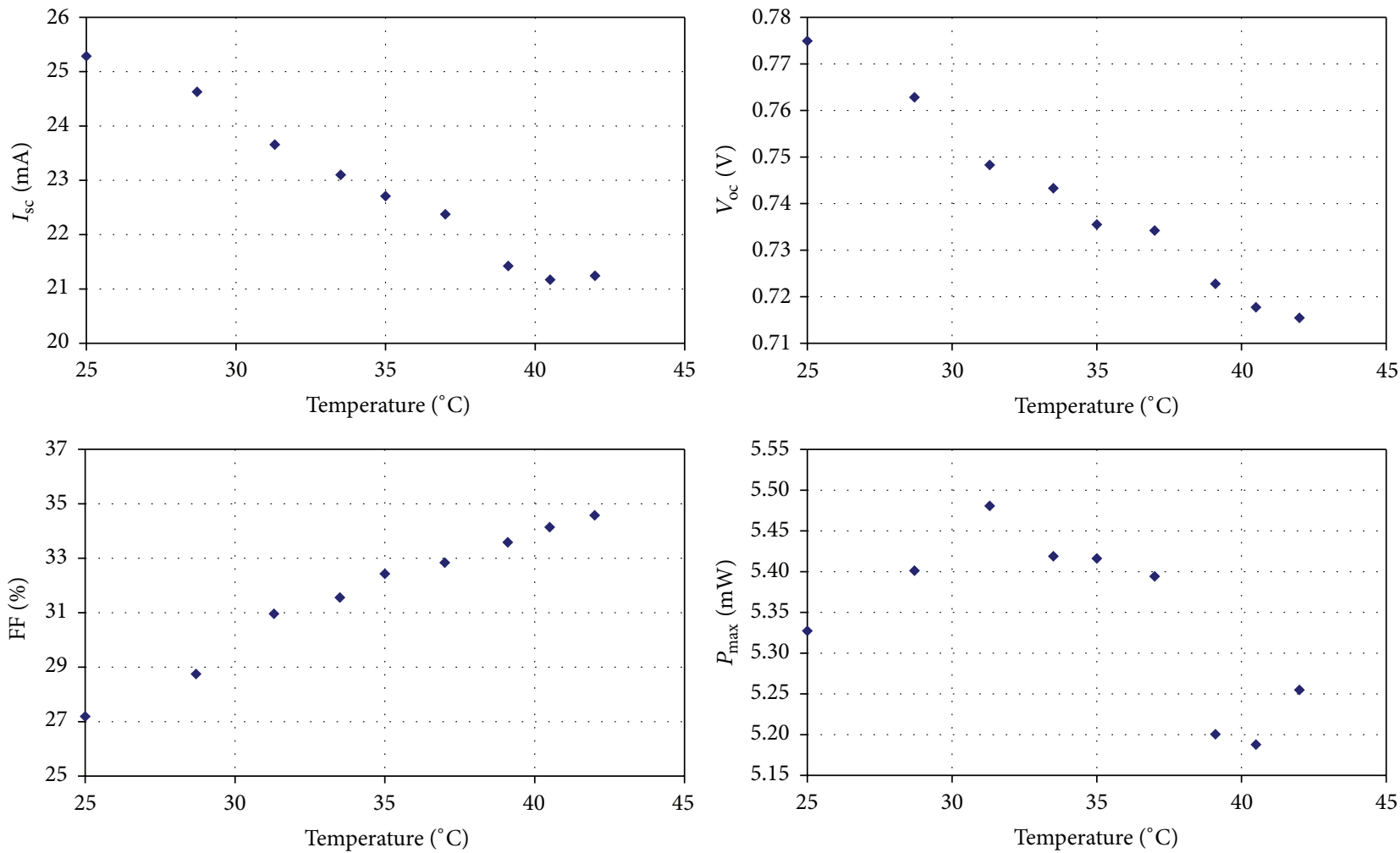

$$
\begin{aligned}
& I_{\mathrm{sc}}: \alpha \approx-0.26 \mathrm{~mA} /{ }^{\circ} \mathrm{C} \\
& V_{\mathrm{oc}}: \beta \approx-3.6 \mathrm{mV} /{ }^{\circ} \mathrm{C} \\
& P_{\max }: \gamma \approx \text { nonlinear } \\
& I_{\mathrm{sc}}: \alpha \approx-0.26 \mathrm{~mA} /{ }^{\circ} \mathrm{C} \\
& V_{\mathrm{oc}}: \beta \approx-3.6 \mathrm{mV} /{ }^{\circ} \mathrm{C}
\end{aligned}
$$

FIGURE 8: Variation of the main electrical parameters of DSC-1 with the temperature, at an irradiance value of $830 \mathrm{~W} / \mathrm{m}^{2}$.

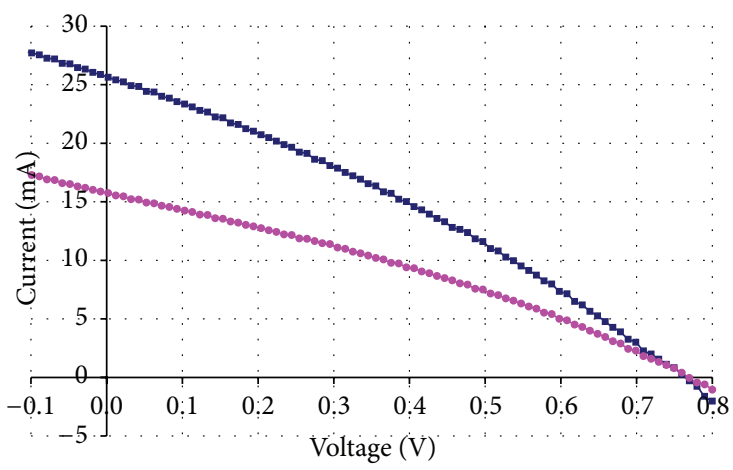

$\rightarrow$ DSSC-1 outdoor

$\longrightarrow$ DSSC-2 outdoor

\begin{tabular}{|c|c|c|c|c|c|c|c|c|}
\hline Solar cell & $\begin{array}{c}V_{\text {oc }} \\
(\mathrm{V})\end{array}$ & $\begin{array}{c}I_{\mathrm{sc}} \\
(\mathrm{mA})\end{array}$ & $\begin{array}{c}P_{\max } \\
(\mathrm{mW})\end{array}$ & $\begin{array}{c}V_{\max } \\
(\mathrm{V})\end{array}$ & $\begin{array}{c}I_{\max } \\
(\mathrm{mA})\end{array}$ & $\begin{array}{c}\text { FF } \\
(\%)\end{array}$ & $\begin{array}{c}\text { Area } \\
\left(\mathrm{cm}^{2}\right)\end{array}$ & $\begin{array}{c}\text { Ef } \\
(\%)\end{array}$ \\
\hline DSC-1 & 0.76 & 25.7 & 6.09 & 0.38 & 15.9 & 31.0 & 6.0 & 1.01 \\
\hline DSC-2 & 0.77 & 15.8 & 3.91 & 0.41 & 9.5 & 32.3 & 6.0 & 0.65 \\
\hline
\end{tabular}

FIgURE 9: Outdoor $I V$-curves of DSC-1 and DSC-2 $\left(38^{\circ} \mathrm{C}, 1015 \mathrm{~W} / \mathrm{m}^{2}\right)$.

The most important data, extracted from these measurements, is the large improvement of the fill factor when the irradiance value decreases. Apparently, the dependency of the FF with the irradiance level follows a linear tendency. The slope of said tendency is so considerable that, as an example, the value of the FF at $200 \mathrm{~W} / \mathrm{m}^{2}$ is practically double compared to the value at $1000 \mathrm{~W} / \mathrm{m}^{2}$.

Finally, despite the $I_{\mathrm{sc}}$ and $V_{\mathrm{oc}}$ tendency, the electrical efficiency of the cell improves notably when irradiance decreases, due to the significant improvement of the FF 


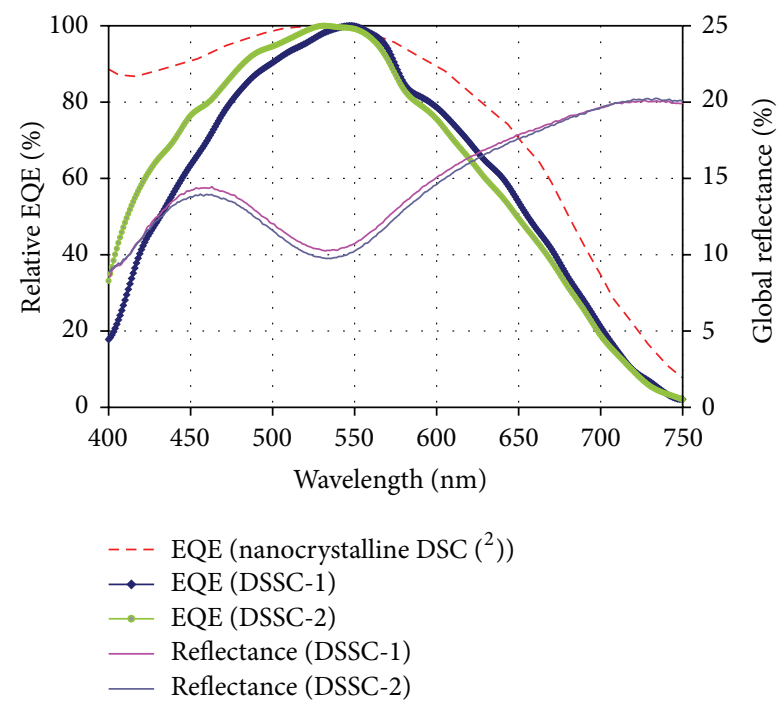

FIGURE 10: Relative External Quantum Efficiency (EQE) and global reflectance of DSC-1 and DSC-2 and EQE measurement of a reference dye-sensitized cell.

at low irradiance levels. Under $1 / 5$ of sun conditions, the efficiency increases to a remarkable $1.8 \%$. As demonstrated here, DSC devices are known to perform well under difficult light conditions such as low illumination or diffuse/indirect illumination, under which 1st- and 2nd-generation PV technologies tend to suffer a loss of performance.

\subsubsection{Temperature Coefficients of the Main Electrical Param-} eters. In order to study the influence of the temperature on the electrical behavior of the textile-based DSC, we carried out some $I V$-curve measurements at different temperatures, maintaining the irradiance value constant at $830 \mathrm{~W} / \mathrm{m}^{2}$. Figure 7 shows the $I V$-curves measured at 6 different temperatures at constant irradiance level $\left(830 \mathrm{~W} / \mathrm{m}^{2}\right)$ for DSC-1.

As presented in Figure 7, $I V$-curve shape changes significantly with temperature variation. Figure 8 shows the variation of $I_{\mathrm{sc}}, V_{\mathrm{oc}}, \mathrm{FF}$, and $P_{\max }$ with the cell temperature for the case of the DSC-1. The keys of the figure show the value of the temperature coefficients for $I_{\mathrm{sc}}, V_{\mathrm{oc}}$, and $P_{\max }$ parameters.

As can be seen in Figure $8, I_{\mathrm{sc}}$ and $V_{\text {oc }}$ parameters show a negative variation with temperature, meaning that their value decreases when temperature increases. Nevertheless, the most important information extracted from this data is the improvement of the FF parameter when temperature increases. Simultaneously as $I_{\mathrm{sc}}$ and $V_{\mathrm{oc}}$ decrease, the maximum power $\left(P_{\max }\right)$ remains practically constant with the temperature variation. This represents a very important advantage for these types of cells in comparison to other PV technologies as crystalline silicon based solar cells, which suffer significant $P_{\max }$ reduction with increasing temperature.

3.2.3. Outdoor IV-Curve Measurement. As a complementary study of the measurements carried out in the solar simulator, $I V$-curve measurements were also performed outdoors to test the electrical behavior of the cell under real conditions. The main advantage of the outdoor measurement is that the data does not require any spectral mismatch correction, but the disadvantage is the inability to control the irradiance level. Both irradiance and cell temperature were also measured during the test.

The $I V$-curves were measured on a sunny day by placing the PV cells on a solar tracker, perfectly adjusted to the sun. The global irradiance during the $I V$-curve measurements varied between $1010 \mathrm{~W} / \mathrm{m}^{2}$ and $1020 \mathrm{~W} / \mathrm{m}^{2}$, and the cell temperature fluctuated between $37^{\circ} \mathrm{C}$ and $39^{\circ} \mathrm{C}$. The measurements obtained for both DSC samples are shown in Figure 9. As shown from Figure 9, the results of the outdoor measurements are quite similar to the results obtained in the solar simulator.

\subsubsection{Spectral Response and Global Reflectance Measurement.} The measurement of the spectral response of dye-sensitized solar cells is not a trivial matter. The time response of these cells is quite slow compared to other technologies and, as a consequence, very low frequencies must be used in the chopping process of the light during the spectral response measurement. Besides this fact, the spectral response of the cells presents a clear dependence with the bias light intensity used to polarize the cell during the measurement.

Figure 10 shows the relative External Quantum Efficiency (EQE) measured for both cells (DSC-1 and DSC-2). The global reflectance as a function of the wavelength is also included in the graph. Finally, as a comparison, the EQE measurement of a similar dye-sensitized cell (deposited on glass) is also included.

As can be seen in Figure 10, the relative spectral response of both cells (DSC-1 and DSC-2) is quite similar. The photogeneration wavelength range of these cells goes from $400 \mathrm{~nm}$ to $750 \mathrm{~nm}$ and shows a maximum around $550 \mathrm{~nm}$. Comparing these results with the EQE values extracted from the bibliography for similar dye-sensitized solar cells (deposited on glass), it can be said that the spectral response is quite similar, with a slight worse performance, especially in the short wavelength range $(<550 \mathrm{~nm})$.

3.2.5. Stability Study. In order to complete the electrical characterization of the textile-based DSC, a study of the stability of their electrical response with the increase of the exposition time was carried out. In the first part of this stability study, DSC-2 was irradiated with a constant intensity of $830 \mathrm{~W} / \mathrm{m}^{2}$, and the temperature of the cell was maintained practically constant between $30^{\circ} \mathrm{C}$ and $31^{\circ} \mathrm{C}$. Different $I V$ curves were measured during the exposition time. Figure 11 shows the evolution of the electrical parameters $\left(I_{\mathrm{sc}}, V_{\mathrm{oc}}, \mathrm{FF}\right.$, and $\left.P_{\max }\right)$ as a function of the exposure time.

All electrical parameters show a slight variation with the exposure time: $I_{\mathrm{sc}}$ and $V_{\mathrm{oc}}$ exhibit a slight improvement with exposure time. The behavior of the FF is just the opposite of its value decreasing with the exposure time. The variation of the FF provokes that the maximum power $\left(P_{\max }\right)$ of the cell also decreases when exposure time increases. Independently of the tendency, the progress of the 4 parameters is quite similar. They show a rapid change in the first minutes of exposure $(\approx 15$ 

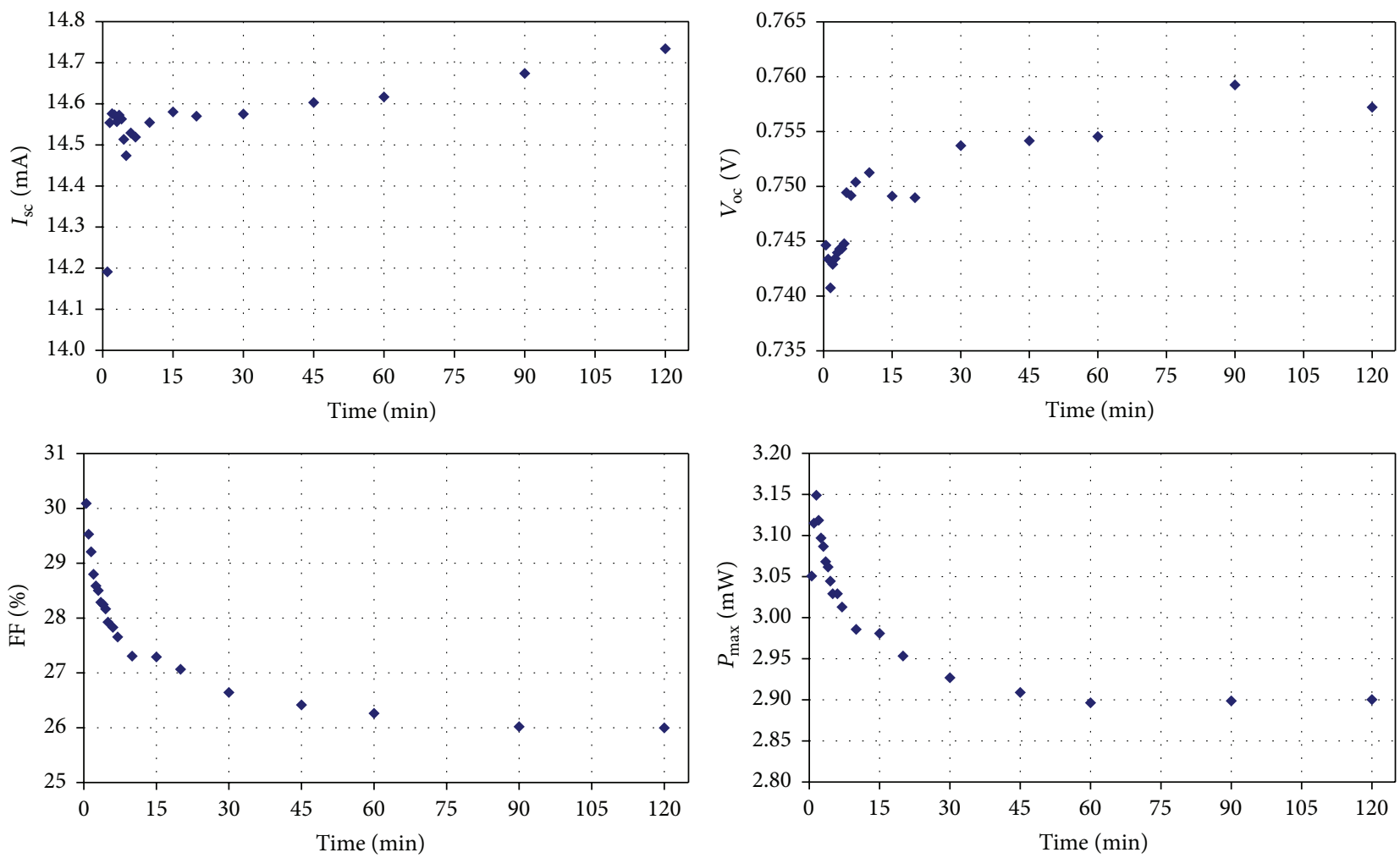

FIgURE 11: Evolution of the main electrical parameters with exposure time at $830 \mathrm{~W} / \mathrm{m}^{2}$ at $30-31^{\circ} \mathrm{C}$.

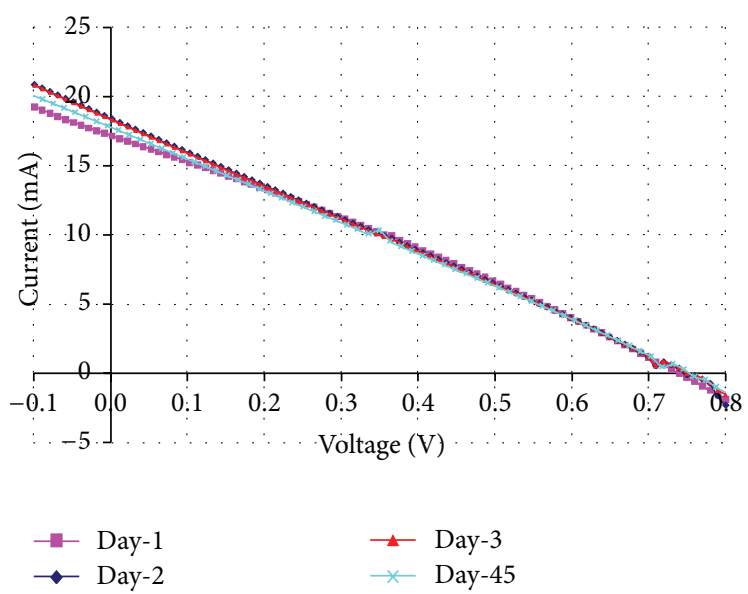

\begin{tabular}{|c|c|c|c|c|c|c|c|c|}
\hline Day & $\begin{array}{c}V_{\text {oc }} \\
(\mathrm{V})\end{array}$ & $\begin{array}{c}I_{\mathrm{sc}} \\
(\mathrm{mA})\end{array}$ & $\begin{array}{c}P_{\max } \\
(\mathrm{mW})\end{array}$ & $\begin{array}{c}V_{\max } \\
(\mathrm{V})\end{array}$ & $\begin{array}{c}I_{\max } \\
(\mathrm{mA})\end{array}$ & $\begin{array}{c}\mathrm{FF} \\
(\%)\end{array}$ & $\begin{array}{c}\text { Area } \\
\left(\mathrm{cm}^{2}\right)\end{array}$ & $\begin{array}{c}\mathrm{Ef} \\
(\%)\end{array}$ \\
\hline 1 & 0.74 & 17.2 & 3.6 & 0.37 & 10.0 & 28.7 & 6.0 & 0.61 \\
\hline 2 & 0.75 & 18.4 & 3.7 & 0.36 & 10.4 & 26.8 & 6.0 & 0.61 \\
\hline 3 & 0.75 & 18.4 & 3.7 & 0.36 & 10.4 & 26.8 & 6.0 & 0.61 \\
\hline 45 & 0.75 & 17.7 & 3.6 & 0.35 & 10.3 & 27.1 & 6.0 & 0.60 \\
\hline
\end{tabular}

Figure 12: $I V$-curves measured in 4 different days for DSC-2. (Irradiance: $830 \mathrm{~W} / \mathrm{m}^{2}$, Temperature: $25^{\circ} \mathrm{C}$.)

minutes) and, after this period of time, the variation with time slows down. After 2 hours of exposure, the efficiency remains almost stable.

Finally, we studied the stability/durability of the textilebased DSC over time. Figure 12 shows the $I V$-curves of
DSC-2 obtained after 3 consecutive days and 45 days after the first experiment, and the electrical parameters were extracted from them. The figure demonstrates the stability of the electrical behavior of our DSC, at least in dark-stored conditions. 


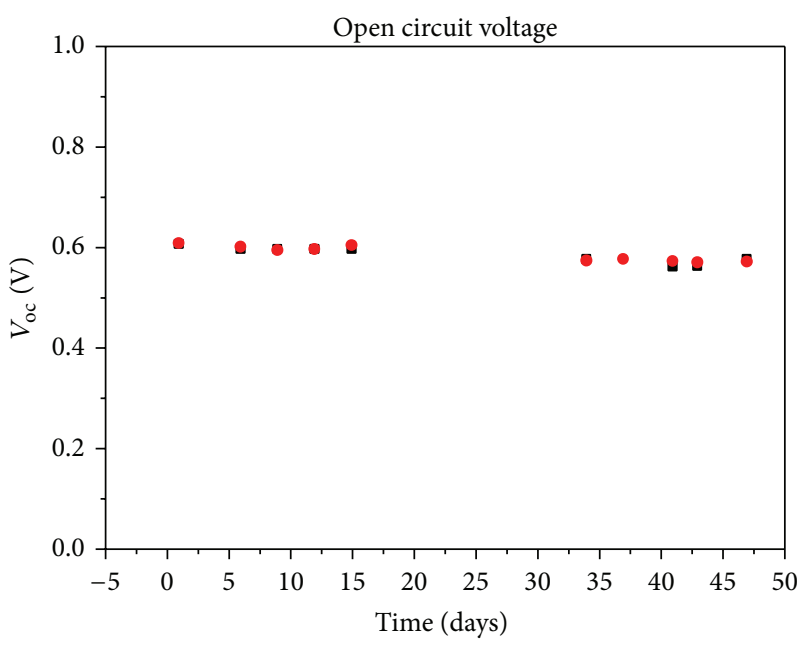

- DSSC-1

- DSSC-2

FIgURE 13: Characterization of $V_{\text {oc }}$ over a period of 7 weeks.

In addition, the open circuit voltage, the current density, and the fill factor of the DSC samples were measured over a period of 7 weeks. All parameters show no significant loss of cell performance over the investigated period (data for $V_{\mathrm{oc}}$ exemplarily shown in Figure 13).

\section{Conclusions}

Solar energy conversion is an object of continuous research, focusing on improving the energy efficiency as well as the structure of photovoltaic cells. With efficiencies continuously increasing, state-of-the-art PV cells offer a good solution to harvest solar energy. However, it is important to understand that available, inflexible PV structures cannot be integrated in many common products, and especially textiles, although they are often directly exposed to sunlight and represent ideal substrates for the conversion of solar energy. Outdoor textiles such as blinds, tents, tarpaulins, and sails, and finally the increasing market of textile architecture, exhibit an outstanding potential to form the basis for flexible, lightweight, and robust PV structures.

Compared to conventional silicon based photovoltaic technology, DSC technology promises a lower cost in manufacture. Because of greatly reduced sensitivity to angle of incidence of radiation and shadowing, DSC produces electricity more efficiently, including low light conditions. In addition, they can be directly incorporated into buildings by replacing conventional glass panels rather than taking up roof or extra land area. Moreover, advantages include not necessitating the use of high-priced raw materials, a manufacturing process that does not produce toxic emissions, and the potential for a rapid efficiency enhancement.

We demonstrated successfully the development of a new two-dimensional textile-based dye-sensitized solar cell, which exploits the typical inherent properties of fabrics such as flexibility, low weight, and mechanical robustness. We apply our DSC design on a heat-resistant glass-fiber fabric due to the necessity of high-temperature processes during the manufacture and report on all further needed conductive, photoactive, and protective materials and their deposition techniques to achieve flexible, light, and mechanically strong textile-based DSC. Our produced large-area devices (up to $6 \mathrm{~cm}^{2}$ per individual unit) show efficiencies up to $1.8 \%$ at $1 / 5$ of the sun. Stability tests assure no loss of photovoltaic activity of the noncorrosive and liquid-proof devices over a period of at least seven weeks.

Therefore, our technology has paved the way for a new generation of flexible photovoltaic devices, which can be used for the generation of power in the mentioned applications as well as in modern textile architecture. This can be considered as a "breakthrough" in textile DSC technology and will promise a quick launch into market after some aspects on the durability in the day-to-day life are assured by various stress tests and the efficiency is improved to a level of $>3 \%$. In the near future, further research should be focused on the development of new titanium inks, low temperature curing processes, and the implementation of solid-state or quasisolid-state electrolytes, which enables the use of other typical fiber forming polymers such as polyesters and polyamides as textile substrates for textile-based DSC.

\section{Competing Interests}

The authors declare that there are no competing interests regarding the publication of this paper.

\section{Acknowledgments}

The authors would like to thank the European Commission for the financial support of the FP7, NMP project NMP2SE-2008-214459 "DEPHOTEX-Development of Photovoltaic Textiles based on novel fibres."

\section{References}

[1] R. W. Miles, G. Zoppi, and I. Forbes, "Inorganic photovoltaic cells," Materials Today, vol. 10, no. 11, pp. 20-27, 2007.

[2] M. A. Green, K. Emery, Y. Hishikawa, W. Warta, and E. D. Dunlop, "Solar cell efficiency tables (version 47)," Progress in Photovoltaics: Research and Applications, vol. 24, no. 1, pp. 3-11, 2016.

[3] M.-E. Ragoussi and T. Torres, "New generation solar cells: concepts, trends and perspectives," Chemical Communications, vol. 51, no. 19, pp. 3957-3972, 2015.

[4] B. O’Regan and M. Grätzel, "A low-cost, high-efficiency solar cell based on dye-sensitized colloidal $\mathrm{TiO}_{2}$ films," Nature, vol. 353, no. 6346, pp. 737-740, 1991.

[5] H. S. Jung and J.-K. Lee, "Dye sensitized solar cells for economically viable photovoltaic systems," Journal of Physical Chemistry Letters, vol. 4, no. 10, pp. 1682-1693, 2013.

[6] S. Mathew, A. Yella, P. Gao et al., "Dye-sensitized solar cells with $13 \%$ efficiency achieved through the molecular engineering of porphyrin sensitizers," Nature Chemistry, vol. 6, no. 3, pp. 242247, 2014.

[7] M. Grätzel, "Perspectives for dye-sensitized nanocrystalline solar cells," Progress in Photovoltaics, vol. 8, no. 1, pp. 171-185, 2000 . 
[8] M. Grätzel, "Recent advances in sensitized mesoscopic solar cells," Accounts of Chemical Research, vol. 42, no. 11, pp. 17881798, 2009.

[9] H. Lindström, A. Holmberg, E. Magnusson, S.-E. Lindquist, L. Malmqvist, and A. Hagfeldt, "A new method for manufacturing nanostructured electrodes on plastic substrates," Nano Letters, vol. 1, no. 2, pp. 97-100, 2001.

[10] C. Longo, J. Freitas, and M.-A. De Paoli, "Performance and stability of $\mathrm{TiO}_{2}$ /dye solar cells assembled with flexible electrodes and a polymer electrolyte," Journal of Photochemistry and Photobiology A: Chemistry, vol. 159, no. 1, pp. 33-39, 2003.

[11] D. Zhang, T. Yoshida, T. Oekermann, K. Furuta, and H. Minoura, "Room-temperature synthesis of porous nanoparticulate $\mathrm{TiO}_{2}$ films for flexible dye-sensitized solar cells," Advanced Functional Materials, vol. 16, no. 9, pp. 1228-1234, 2006.

[12] S. I. Cha, Y. Kim, K. H. Hwang, Y.-J. Shin, S. H. Seo, and D. Y. Lee, "Dye-sensitized solar cells on glass paper: TCO-free highly bendable dye-sensitized solar cells inspired by the traditional Korean door structure," Energy and Environmental Science, vol. 5, no. 3, pp. 6071-6075, 2012.

[13] Y. Fu, Z. Lv, S. Hou et al., "TCO-free, flexible, and bifacial dyesensitized solar cell based on low-cost metal wires," Advanced Energy Materials, vol. 2, no. 1, pp. 37-41, 2012.

[14] X. Fan, F. Wang, Z. Chu, L. Chen, C. Zhang, and D. Zou, "Conductive mesh based flexible dye-sensitized solar cells," Applied Physics Letters, vol. 90, no. 7, Article ID 073501, 2007.

[15] H. Dai, Y. Zhou, L. Chen et al., "Porous ZnO nanosheet arrays constructed on weaved metal wire for flexible dye-sensitized solar cells," Nanoscale, vol. 5, no. 11, pp. 5102-5108, 2013.

[16] H. Wang, Y. Liu, H. Huang et al., "Low resistance dye-sensitized solar cells based on all-titanium substrates using wires and sheets," Applied Surface Science, vol. 255, no. 22, pp. 9020-9025, 2009.

[17] X. Fan, Z. Z. Chu, F. Z. Wang et al., "Wire-shaped flexible dyesensitized solar cells," Advanced Materials, vol. 20, no. 3, pp. 592-595, 2008.

[18] K. Cherenack, C. Zysset, T. Kinkeldei, N. Münzenrieder, and G. Tröster, "Woven electronic fibers with sensing and display functions for smart textiles," Advanced Materials, vol. 22, no. 45, pp. 5178-5182, 2010.

[19] T. Chen, L. Qiu, Z. Cai et al., "Intertwined aligned carbon nanotube fiber based dye-sensitized solar cells," Nano Letters, vol. 12, no. 5, pp. 2568-2572, 2012.

[20] Z. Lv, J. Yu, H. Wu et al., "Highly efficient and completely flexible fiber-shaped dye-sensitized solar cell based on $\mathrm{TiO}_{2}$ nanotube array," Nanoscale, vol. 4, no. 4, pp. 1248-1253, 2012.

[21] H. Sun, H. Li, X. You et al., "Quasi-solid-state, coaxial, fibershaped dye-sensitized solar cells," Journal of Materials Chemistry A, vol. 2, no. 2, pp. 345-349, 2014.

[22] Y. Fu, Z. Lv, S. Hou et al., "Conjunction of fiber solar cells with groovy micro-reflectors as highly efficient energy harvesters," Energy and Environmental Science, vol. 4, no. 9, pp. 3379-3383, 2011.

[23] M. Peng, S. Hou, H. Wu et al., "Integration of fiber dyesensitized solar cells with luminescent solar concentrators for high power output," Journal of Materials Chemistry A, vol. 2, no. 4, pp. 926-932, 2014. 

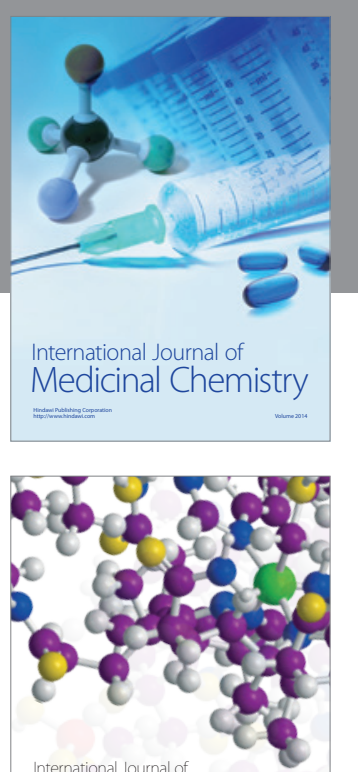

Carbohydrate Chemistry

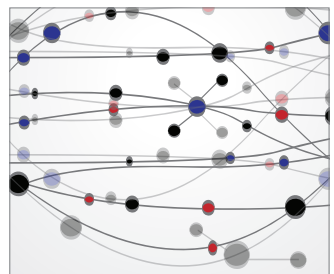

The Scientific World Journal
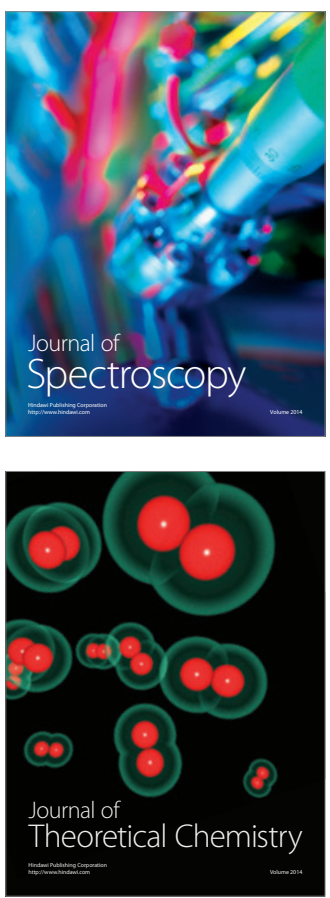
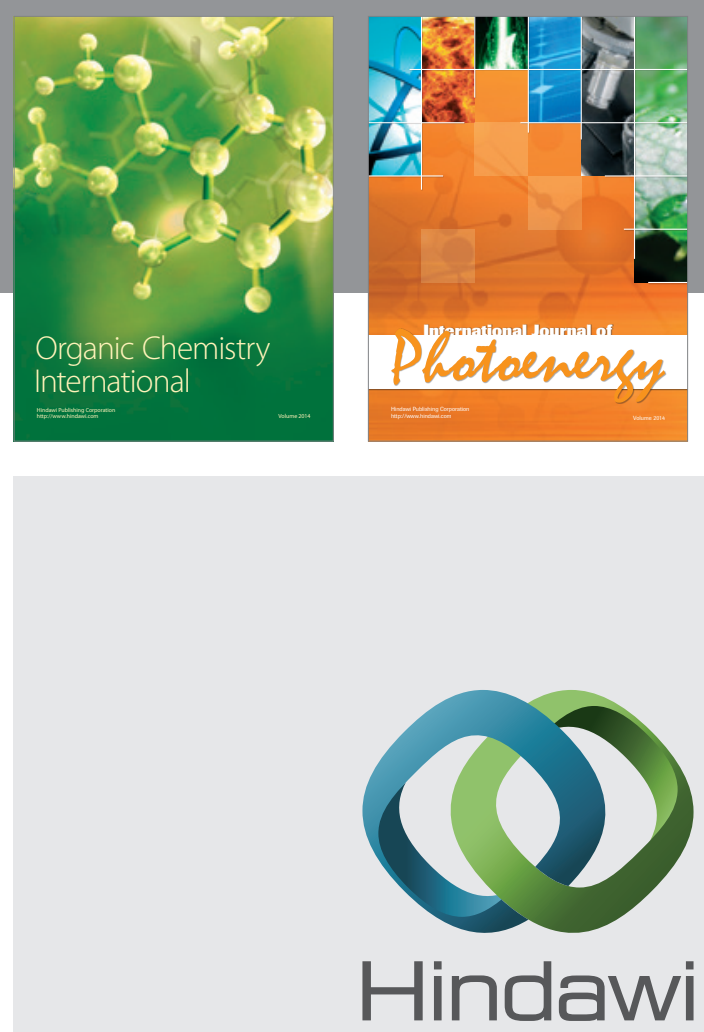

Submit your manuscripts at

http://www.hindawi.com

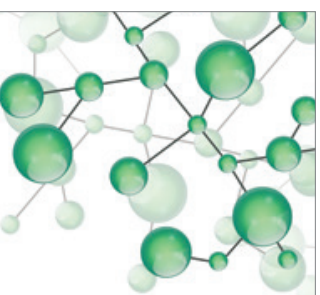

International Journal of

Inorganic Chemistry

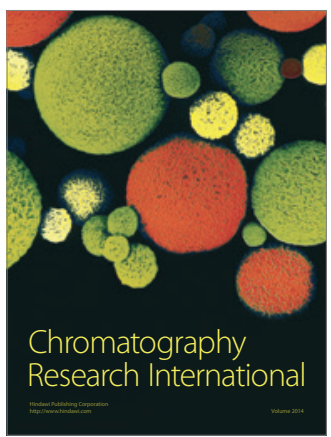

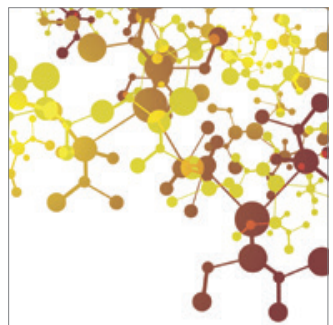

Applied Chemistry
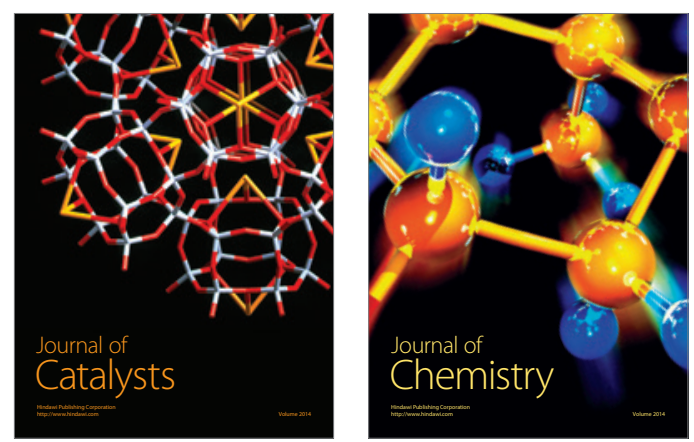
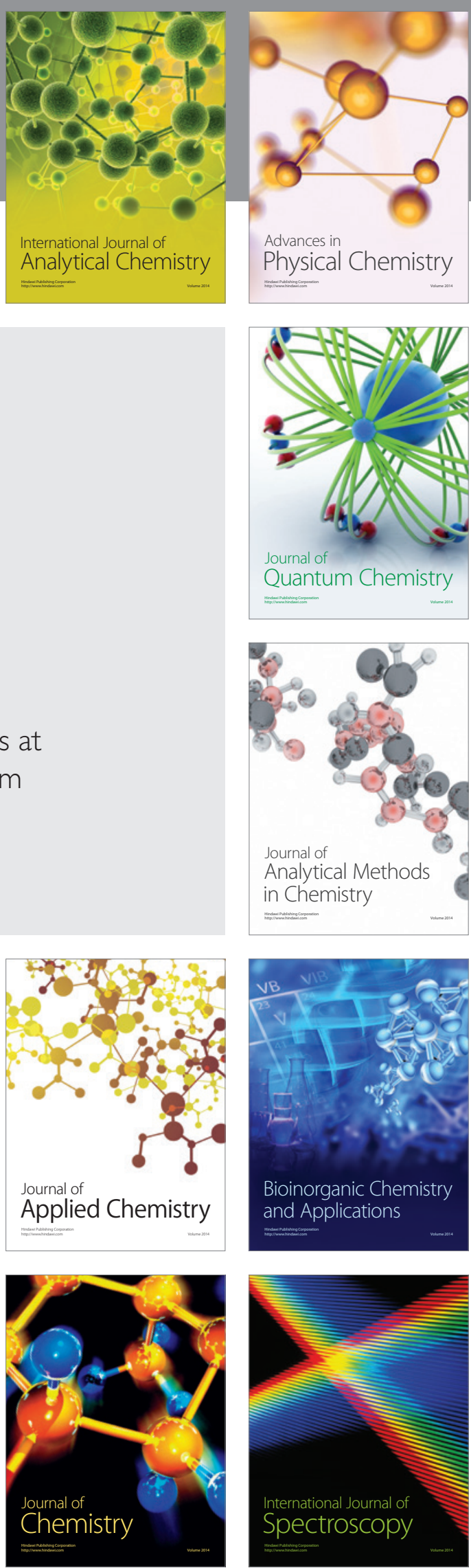